\title{
UMA CARTA PARA MIM MESMA TRÊS ANOS ATRÁS: UM OLHAR PARA O PNAIC ${ }^{1}$ A PARTIR DAS NARRATIVAS DE PROFESSORAS
}

EVERALDO GOMES LEANDRO²

Universidade Federal de São Carlos

LIIVIA DE OLIVEIRA VASCONCELOS 3

Universidade Federal de São Carlos

RESUMO O presente estudo, elaborado no formato de carta, tem como remetentes dois Educadores Matemáticos que participaram das ações do Pacto Nacional pela Alfabetização na Idade Certa (PNAIC), nos três primeiros anos do programa e que seguem interpretando essa experiência. Ao propor que as professoras escrevessem cartas endereçadas a elas mesmas no passado, três anos atrás, os narradores se questionam: "O que revelam as cartas produzidas por professoras em um contexto de formação continuada?" Ao investigar o conteúdo dessas cartas, tem-se por objetivo refletir sobre as ações do PNAIC, a partir dos indícios encontrados nas narrativas das professoras. As cartas revelaram uma trajetória profissional caracterizada pela resiliência docente e evidenciaram que o PNAIC se constituiu em um espaço de diálogo entre os pares, como uma oportunidade de manter-se em formação e como um disparador para mudanças na forma de alfabetizar as crianças.

Palavras-chave: Programa de formação continuada. Educação matemática. Formação de professores.

\section{ABSTRACT A LETTER TO MYSELF THREE YEARS AGO: A LOOK AT THE PNAIC FROM THE TEACHERS' NARRATIVES}

The present study, written in the letter format, is sent by two Mathematical Educators who took part of the Pacto Nacional pela Alfabetização na Idade Certa (PNAIC) in the first three years of the program and who continue to interpret this experience. In proposing for

1 Pacto Nacional pela Alfabetização na Idade Certa.

2 Apoio parcial: Conselho Nacional de Desenvolvimento Científico e Tecnológico (CNPq). Processo no: 140220/2017-8.

3 Apoio parcial: Coordenação de Aperfeiçoamento de Pessoal de Nivel Superior - Brasil (CAPES) - Código de Financiamento 001. 
teachers to write letters addressed to themselves in the past three years ago, the narrators question themselves: "What do the letters produced by teachers in a context of continuing formation reveal?" By investigating the content of these letters, it is intended to reflect about the actions of the PNAIC from the clues found in the teachers' narratives. The letters revealed a professional trajectory by teacher resilience and showed that the PNAIC was a space for dialogue among peers, as an opportunity to maintain in training and as a trigger for changes in the way children are literate.

Keywords: Continuing education program. Mathematical education. Teacher training

\section{RESUMEN UNA CARTA PARA MII MISMA HACE TRES AÑOS: UNA MIRADA AL PNAIC A PARTIR DE LAS NARRATIVAS DE PROFESORAS}

El presente estudio, elaborado en formato de carta, tiene como remitentes dos Educadores Matemáticos que participaron en las acciones del Pacto Nacional pela Alfabetização na Idade Certa (PNAIC) en los tres primeros años del programa y que siguen interpretando esa experiencia. Al proponer que las profesoras escribieran cartas dirigidas a ellas mismas en el pasado, hace tres años, los narradores se cuestionan: “¿Qué revelan las cartas producidas por profesoras en un contexto de formación continuada?" Al investigar el contenido de esas cartas se tiene por objetivo reflexionar sobre las acciones del PNAIC a partir de los indicios encontrados en las narrativas de las profesoras. Las cartas revelaron una trayectoria profesional caracterizada por la resiliencia docente y evidenciaron que el PNAIC se constituyó en un espacio de diálogo entre los pares, como una oportunidad de mantenerse en formación y como un disparador para cambios en la forma de alfabetizar a los niños.

Palabras clave: Programa de formación continua. Educación matemática. Formación de profesores. 


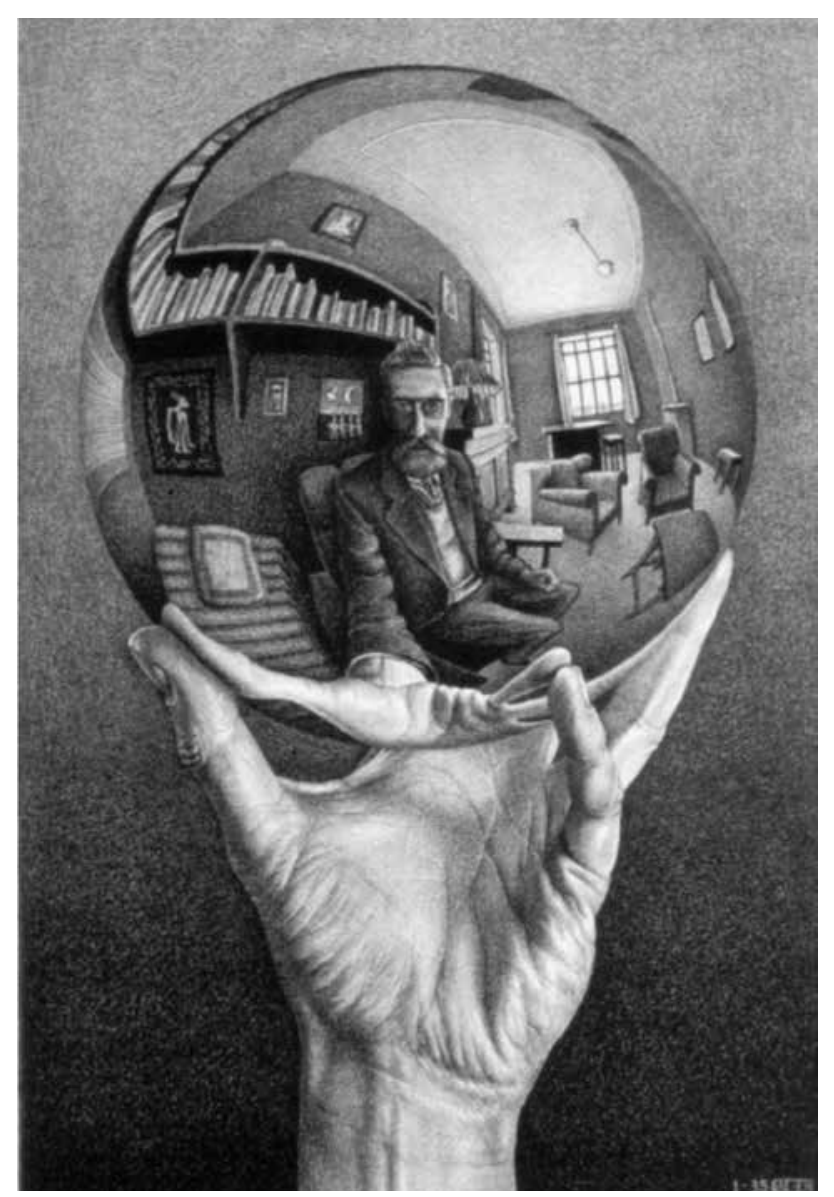

Hand with Reflecting Sphere, 1935.

M. C. Escher

\section{Caro leitor,}

Quem the escreve são dois educadores matemáticos que participaram do PNAIC/UFSCar4: Everaldo e Lívia, na função de Formadores de Professoras que ensinam matemática.

Para compartilhar a pesquisa desenvolvida por nós, optamos pela escrita do texto em formato de carta, pois a ciência pós-moderna “inventa novos contextos persuasivos e novos estilos e gêneros de escrita científica" (SUASSUNA, 2008, p. 347). Defendemos que o gênero textual carta facilitará nossa interlocução com pesquisadores da área, visto que apresentará o escopo teórico-metodológico em uma dinâmica semelhante ao processo de desenvolvimento da própria pesquisa. Concordamos com

4 Pacto Nacional de Alfabetização na Idade Certa/ Universidade Federal de São Carlos. Nos parágrafos seguintes explicaremos que programa é este.
Bakhtin (1997, p. 286) que "quando passamos o estilo de um gênero para outro, não nos limitamos a modificar a ressonância deste estilo graças à sua inserção num gênero que não lhe é próprio, destruímos e renovamos o próprio gênero". Nesse sentido, destruiremos o gênero artigo científico tradicional e o renovaremos, ao comunicar ideias científicas por meio desta carta.

A história que contaremos a seguir ocorreu em uma tarde bastante chuvosa de novembro de 2015. Era um encontro de formação de professoras, e a pancada de água nos impediu de retornar para as salas de aula. Reunidos em um auditório da UFSCar, continuamos a programação que faríamos com as professoras nas salas. Assim, distribuímos papel e caneta e pedimos que as professoras escrevessem sobre elas mesmas.

Nossa proposta era que as professoras escrevessem uma carta. Não uma carta destinada a outra pessoa, mas, sim, uma carta para si mesmas há três anos atrás. Ou seja, a professora deveria imaginar quais palavras seriam capazes de motivá-la, prepará-la e acalentá-la durante seu ingresso no PNAIC.

Tal proposta partiu, em primeiro lugar, do pressuposto de que escrever sobre si é uma prática (auto)formativa (NACARATO, 2015). Ao longo do nosso processo formativo, pudemos constatar tal afirmação, pois desenvolvemos diferentes formas de escrita de si. Seja em nossos memoriais de formação, por exemplo, quando escrevemos e refletimos sobre a experiência vivida no estágio supervisionado, sobre a participação no Programa Institucional de Bolsas de Iniciação à Docência (PIBID) ou em grupos de estudo e pesquisa, sobre os medos e as angústias de sermos professores em formação inicial, sobre a avaliação em aulas de Matemática, entre outros assuntos. Seja em nossos registros reflexivos, nos quais pudemos (re)pensar a organização do ensino e seu de- 
senvolvimento em sala de aula. Seja em nossos relatos de experiência, em que pudemos refletir e compartilhar práticas de sala de aula que consideramos significativas, ou em nossos portfólios, quando escrevemos narrativas de aula.

Essas diferentes formas de escrita de si não somente possibilitaram a reflexão sobre o processo formativo singular de cada um de nós, mas também nos deram indícios (GINZBURG, 1989) sobre elementos para refletir, por exemplo, sobre a estrutura do estágio supervisionado, sobre os programas de formação de professores, sobre o papel de outros espaços para a formação de professores e sobre os processos avaliativos e/ou os currículos, por exemplo. Tais reflexões, além de dar sentido ao que foi vivido, nos ajudaram a criar nossas memórias de futuro (BAKHTIN, 1997) e nosso próprio futuro (GALVÃO, 2005).

Em segundo lugar, um pressuposto que nos motivou a desenvolver a proposta é que, aqui no Brasil, pesquisadores, como Gama e Sousa (2011), Nacarato e Passeggi (2013), Santos, Miarka e Siple (2014), Silva e Passos (2016) e Crecci (2016) utilizaram diferentes formas de escrita de si como fonte de suas pesquisas e também constataram que essas escritas indicam elementos para pensar a docência, o professor, o ensino, a aprendizagem, entre outros aspectos.

Concordamos com Clandinin e Connelly (2015, p. 27) que "as histórias vividas e contadas educam a nós mesmos e aos outros". A escrita de si pode se constituir como narrativa, e ela nos possibilita estudar e investigar as experiências (FREITAS; FIORENTINI, 2007).

A narrativa, que pode ser oral ou escrita, nos auxilia a perceber outras possibilidades de prática, e essa percepção surge a partir da interpretação do passado e da consciência de que essa interpretação está aberta a outras. 0 presente é, assim, o momento de reflexão do narrador, e o futuro é entendido como horizonte de expectativa (NACARATO, 2015).

Dessa forma, caro leitor, a narrativa que aqui compomos, bem como as outras que serão apresentadas, é constituída por três elementos: sua temporalidade, seu contexto e o lugar físico em que a trama se desenvolve. 0 tempo, esse "compositor de destinos, tambor de todos os ritmos", ${ }^{5}$ é um dos elementos centrais das narrativas e influencia a composição narrativa de diferentes maneiras, pois há o tempo da narrativa em si, há o tempo histórico em que a narrativa foi escrita e há a percepção de tempo do narrador (CRECCI, 2016).

O texto narrativo tem como outro elemento o contexto: a narrativa é permeada por contornos institucionais, sociais e culturais (CRECCI, 2016). Assim, ao ouvir/ler as produções narrativas de professores, é possivel analisar os contextos de programas de formação de professores, os currículos prescritos e/ou as normatizações e perceber os sentidos atribuídos pelos sujeitos envolvidos nesses contextos (NACARATO; PASSEGGI, 2013). Nesta carta, por exemplo, desejamos que você conheça mais de perto os contornos do PNAIC e as práticas que nele vivenciamos, fazendo sua interpretação particular sobre o programa e sobre um dos seus muitos desdobramentos, que é a formação de professores que ocorre no PNAIC/ UFSCar.

Também é possivel perceber nas narrativas, além da temporalidade e do contexto, o cenário/lugar fisico em que a trama se desenvolve. Esses três elementos se misturam na composição narrativa (CRECCI, 2016) e fazem da narrativa um modo de "representar a experiência, revivê-la, reconstruí-la e ressignificá-la" (GAMA; SOUSA, 2011, p. 138).

Além disso, a narrativa estrutura-se por um processo reflexivo que integra três momentos:

5 BETHÂNIA, Maria. Oração ao tempo. Disco: Tempo, Tempo, Tempo, Tempo. 2006. Compositor: Caetano Veloso. 
passado, presente e futuro e oportuniza, ao sujeito que narra, identificar relações entre estes três momentos, levando também em conta as conexões com o contexto político, social e cultural em que está imerso.

Pensando nessa perspectiva de narrativa assumida por nós e percebendo suas possibilidades como prática (auto)formativa, durante o Seminário Final do PNAIC, em 2015, ocorrido na Universidade Federal de São Carlos (UFSCar), decidimos propor, para um grupo de 249 professoras Orientadoras de Estudo (OE) ${ }^{6}$ do Pacto Nacional pela Alfabetização na Idade Certa (PNAIC), a construção de uma narrativa, desenvolvida a partir do gênero textual carta.

Sabemos que o PNAIC foi um compromisso formal assumido pelos governos federal do Brasil, do Distrito Federal, dos estados e dos municípios para assegurar a alfabetização das crianças até os 8 anos de idade. 0 Pacto está em consonância com a meta 5 do Plano Nacional de Educação (PNE), que define "alfabetizar todas as crianças, no máximo, até o final do 3.o ano do Ensino Fundamental" (BRASIL, 2014, $s / p)$.

As ações do PNAIC apoiavam-se em quatro eixos de atuação: (1) Formação continuada; (2) Materiais didáticos; (3) Avaliações; (4) Gestão, mobilização e controle social. Em relação ao primeiro eixo, o PNAIC deu início às suas atividades em 2013, focando a alfabetização na língua materna nas atividades de formação com as professoras. Em 2014, o foco foi deslocado para a Matemática nos anos iniciais e, em 2015, o processo de formação centrou-se nas discussões sobre currículo, integração dos

6 Os professores Orientadores de Estudo (OE) são os responsáveis por realizar a formação com os professores alfabetizadores em seus municípios. Tais professores fazem a ponte entre as universidades, com seus programas de formação, e os professores que estão em contato direto com as crianças. Cabe chamar a atenção para o fato de que todos os professores envolvidos no PNAIC recebiam uma bolsa formação do Fundo Nacional de Desenvolvimento da Educação (FNDE). componentes curriculares, organização do trabalho pedagógico e alfabetização.

Durante o Seminário Final de 2015 , nós e os outros integrantes do grupo de formadores do polo do PNAIC da UFSCar estávamos interessados em ter um feedback das professoras Orientadoras de Estudo sobre esses três primeiros anos de PNAIC. Por isso, sugerimos às professoras OE a construção de uma narrativa/carta.

E imaginamos que nessa carta a professora poderia contar para si mesma o percurso triIhado, as escolhas feitas, as alegrias vividas, as suas perdas e os saberes construídos. Também seria muito interessante se ela justificasse para si os motivos pelos quais escolheu o caminho tomado e refletisse sobre as experiências que a modificaram pessoal e profissionalmente.

Por outro lado, por meio das palavras, entendidas aqui como signo ideológico por excelência, como nos ensina Bakhtin (2006), as professoras poderiam indicar as mudanças em seu próprio processo de desenvolvimento profissional, ocorridas e influenciadas pela participação no PNAIC.

Nesta carta, pretendemos interpretar aquelas cartas escritas por três professoras orientadoras de estudo. Para começar nossa interpretação das três narrativas nos perguntamos: "o que revelam as cartas produzidas por professoras em um contexto de formação continuada?" Com essa pergunta, queríamos refletir sobre as ações do PNAIC a partir dos indícios encontrados nas narrativas das professoras.

Na organização desta carta, as narrativas são apresentadas em quatro tópicos: (1) As cartas de formação ou sobre poder dizer tudo que se quer; (2) A interpretação das cartas a partir do paradigma indiciário: um caminho metodológico; (3) As cartas de Bia, Amanda e Cátia; (4) Post scriptum ou das surpresas que chegam quando acreditamos que uma narrativa está finalizada. 


\section{As cartas de formação ou sobre poder dizer tudo que se quer}

- Também gostaria de ser poeta - Disse o carteiro.

- Não, é mais original ser carteiro. Tens de andar muito e não engordas. Nós poetas somos todos gordos. - Respondeu Pablo Neruda.

- Sim, mas com a poesia podia fazer com que as mulheres se apaixonassem por mim. Como é que uma pessoa se torna poeta?

- Tenta caminhar lentamente pela costa até a baía. Olhando à tua volta.

- E elas virão ter comigo, as metáforas?

- Certamente.

- Eu adoraria, seria maravilhoso, poder dizer tudo que quisesse.

- Mas mesmo que não sejas um poeta podes dizer o que quiseres.

(O carteiro e o poeta, 1994).7

O diálogo acima foi extraído do filme $O$ carteiro e o poeta. 0 referido filme nos convida a refletir sobre os diferentes sujeitos sociais que, de alguma forma, trabalham com a linguagem. O carteiro, fascinado pelo que ouve de Neruda, acaba por desejar se expressar pela poesia. E, a partir da sua relação com seu ídolo, começa a se transformar de carteiro em poeta.

Da mesma forma, percebemos o processo de formação que vivenciamos no PNAIC. Assim como o carteiro, as OE relacionam-se diretamente com a linguagem, seja pela ação de alfabetizar os pequenos ou pelos estudos que desenvolvem sobre seu objeto de trabalho. No entanto, sentimos falta de um espaço no qual elas pudessem expressar seus sentidos em relação às experiências vividas durante os três primeiros anos de participação no PNAIC. Se no filme, Pablo Neruda diz para o carteiro que

7 Filme: Il Postino (O carteiro e o poeta - título no Brasil). Direção: Michael Radford. Roteiro adaptado: Anna Pavignano. 1994. não é necessário ser poeta para "dizeres o que queres", em nossa proposta com as professoras, por outro lado, queríamos ouvir o que tinham a dizer sobre o PNAIC, pois entendemos que não é necessário ser a pessoa que escreve a legislação, o currículo prescrito ou a normatização de um programa de formação de professores para dizer sobre a legislação, sobre o currículo ou sobre a normatização.

Para isso, encontramos nas cartas uma alternativa para que pudéssemos ouvir o que as professoras tinham a dizer. A ideia surgiu de uma sessão do blog Hypeness, ${ }^{8}$ chamada "Uma carta para mim mesma 10 anos atrás", na qual as pessoas escreviam cartas para si mesmas no passado.

Optamos pelas cartas também por entender, com Dewey (1971), que as experiências presentes, passadas e futuras, estão intimamente relacionadas, pois há uma continuidade, uma relação; e interpretar uma experiência pressupõe desmistificar elementos dessa relação.

Nos chamou a atenção que as cartas disponibilizadas no blog tinham uma carga emocional e levavam a uma reflexão dos narradores sobre suas vidas.

Percebemos que esse tipo de narrativa, disponibilizada no blog, não era meramente uma descrição de fatos, mas continha aspectos subjetivos e, algumas vezes, interpretativos sobre as experiências vividas. Por essa razão, fizemos a escolha desse gênero textual para o momento de formação.

Há, porém, diferentes tipos de cartas, entre elas: a carta pessoal, a carta argumentativa, a carta ao leitor e a carta aberta. Cada um dos tipos é destinado a um leitor específico, e por isso as palavras escritas variam de acordo com sua finalidade e seu interlocutor.

Compreendendo que as palavras comportam duas facetas que são determinadas pelo

8 Disponivel em: <http://www.hypeness.com.br/>. Acesso em: 03 abr. 2019. 
"fato de que procede de alguém, como pelo fato de que se dirige para alguém" (BAKHTIN, 2006, p. 115), em nossa proposta, entendemos que tínhamos como leitores as próprias $\mathrm{OE}$ e o grupo de formadores do PNAIC. As OE escreviam sobre si e para si e, por isso, se constituíram como as primeiras leitoras; e o grupo de formadores, como tinham por objetivo obter um feedback das OE sobre os três anos do PNAIC, se constituíram em outro grupo de leitores das cartas.

Essas especificidades da proposta de formação em relação aos outros tipos de cartas nos fizeram denominar as cartas produzidas pelas professoras como "cartas de formação".

\section{A interpretação das cartas a partir do paradigma indiciário: um caminho metodológico}

Chegando a este ponto da leitura, você que nos lê já sabe de onde saímos e o que intencionamos fazer por meio desta carta. Antes de the apresentar as cartas das OE, explicaremos 0 processo de leitura e interpretação delas, para que você possa saber quais caminhos metodológicos trilhamos para criar nossa interpretação dessas narrativas.

Diante da proposta de escrever este trabalho, em um primeiro momento, dedicamos um tempo à leitura das cartas. A primeira leitura deu-se de maneira livre e despretensiosa, por não termos um foco específico, um olhar que buscasse identificar algo. Tínhamos como intuito apenas nos deleitar com a trajetória de nossas colegas. Durante esse processo, foi possivel notar que, ao escreverem suas cartas, elas traziam muitos sentimentos de sua vida particular: o envolvimento com a família, com as atividades de lazer. Dewey (1971) complementa que as pessoas precisam ser entendidas do ponto de vista da sua individualidade, mas, ao mesmo tempo, como seres sociais, em constante interação. Segundo ele, a experiência é pessoal e social.

Foi interessante ver que as cartas mostraram que não havia ali um encontro entre o eu profissional de hoje e o eu profissional de três anos atrás - era um encontro de um eu atual com um eu de três anos atrás, que é humano, incompleto, vivido, crítico, ativo e constituído a partir de outros. Dessa forma, a leitura das cartas nos fez sentir próximos das autoras.

A partir da complexidade latente no material que tínhamos em mãos, fizemos escolhas. A primeira foi delimitar as narrativas que seriam interpretadas. Optamos por escolher três cartas que nos dessem indícios para refletir sobre as ações do PNAIC e sobre os sentidos que essas professoras alfabetizadoras atribuíram ao PNAIC durante os três primeiros anos de participação.

A segunda escolha deu-se em relação ao referencial teórico que nos auxiliaria a interpretar as cartas. Percebemos que a maneira de interpretar as cartas estava diretamente ligada à perspectiva de linguagem que temos. Concordamos que a linguagem é uma forma de interação entre as pessoas e ultrapassa as concepções que a concebem somente como expressão do pensamento ou como instrumento de comunicação/ferramenta em uma perspectiva estruturalista (GERALDI, 1984).

Em uma perspectiva estruturalista da linguagem, por exemplo, a interpretação de narrativas pode se dar como proposto por Galvão (2005), apoiada nas pesquisas de William Labov, em que se entende que as narrativas têm propriedades formais e que uma narrativa completa deve incluir seis elementos:

[...] um Resumo (Abstract-sumário da substância da narrativa), Orientação (Orientation - tempo, lugar, situação, participantes), Complicação da ação (Complication- seqüência de acontecimentos), Avaliação (Evaluation - signi- 
ficado e sentido da ação, atitude do narrador), Resolução (Result - o que aconteceu, como foi resolvida a complicação) e Coda (Coda - termina a narrativa, voltando a perspectiva para o presente). (GALVÃO, 2005, p. 333)

Porém nos questionamos: como esperar essa estrutura nas narrativas das professoras? Como a identificação dessa estrutura nas narrativas nos auxiliará na interpretação, se compreendemos a linguagem como forma de interação entre as pessoas?

Uma interpretação dessas narrativas a partir de uma perspectiva paradigmática/estruturalista é, a nosso ver, limitada para tais fins, devido à necessidade de compreender os sentidos atribuídos pelos sujeitos. Como as narrativas também contribuem para a interlocução dos sujeitos, um caminho metodológico possivel para a interpretação das cartas seria pautado no paradigma indiciário de Ginzburg (1989) e em uma perspectiva de linguagem que entende a própria linguagem como forma de interação e compreende que a palavra "é uma espécie de ponte lançada entre mim e os outros. Se ela se apóia sobre mim numa extremidade, na outra apoia-se sobre o meu interlocutor. A palavra é o território comum do locutor e do interlocutor" (BAKHTIN, 2006, p. 115).

O paradigma indiciário proposto por Ginzburg (1989), por sua vez, possibilita perceber, na realidade opaca (sem claridade, sem transparência), indícios, pistas e sinais que permitem decifrá-la, que permitem compreendê-la. É dessa forma que, por exemplo, no livro $O$ queijo e os vermes (GINZBURG, 2006), o autor conta a história de Menocchio, um sujeito do século XVI perseguido pela Inquisição da Igreja Católica por defender que o mundo tinha sua origem na putrefação. A partir dos indícios presentes no acervo de documentos inquisitoriais e tomando como fio condutor a história desse sujeito, Ginzburg (1989) remonta à cultura popular em uma Europa pré-industrial marcada pela Reforma Protestante e pela repressão, nos países católicos, que levou diversas pessoas a serem consideradas bruxas, curandeiros ou benandanti (expressão utilizada no distrito de Friuli, na Itália, para designar feiticeiros).

Ao utilizar o paradigma indiciário como método de interpretação das cartas, Ginzburg (1989) reconhece o caráter indireto do conhecimento, pois sua pesquisa se dá de forma indireta: por meio dos documentos encontrados, faz inferências a partir dos sinais encontrados e valoriza as especificidades do objeto, colocando como fio condutor de sua narrativa os sujeitos deixados de lado ou simplesmente ignorados pelos historiadores.

Ao interpretar as cartas, fizemos esse exercício. A partir das pistas encontradas nas cartas e do convívio com as OE narradoras, desenvolveremos, no próximo tópico, nossas reflexões. Procuramos também circunscrever tanto o que está escrito como a forma como foi interpretado. Baseados em Clandinin e Connelly (2015, p. 58), reconhecemos que é importante "considerar os personagens que vivem as histórias; os personagens que contam as histórias; o momento em que cada história é vivida; o tempo em que foram ou são contadas; o local no qual as histórias são vividas e contadas, e assim por diante".

Para a estrutura da escrita do próximo tópico, optamos por trazer as cartas na íntegra em um primeiro momento (com o intuito de manter/mostrar a forma como as professoras as escreveram) e, em um segundo momento da análise narrativa em si -, retomar os fragmentos/pistas/indícios ${ }^{9}$ que nos são necessários para a interpretação.

9 Os fragmentos/pistas/indícios foram identificados com textos em itálico, nos quais grifamos os trechos que nos chamaram a atenção. 


\section{As cartas de Bia, Amanda e Cátia}

Oi Bia,

Quando você for ler esta carta daqui a 3 anos, você poderá certamente se surpreender muitíssimo, pois as coisas que podem te acontecer são inimagináveis neste momento.

1) Quando você a ler, você estará vivendo o último terço da média de vida dos brasileiros (70 anos), não se assuste com isso; você sempre superou a média.

2) Pense que o trabalho que você faz agora pode te levar a lugares do mundo que você idealizou conhecer, mas que nem sequer imaginou ser possivel, como conhecer as culturas africanas, peruanas e maoris.

3) Você, que sempre adorou uma sala de aula com crianças em ciclo de alfabetização $e$ que tem trabalhado com professores um tanto quanto resistentes em olhar para a diversidade e para o direito do outro, poderá ser convidada a trabalhar com um programa de formação de professores deste ciclo - o PNAIC - e voltar a sentir aquela sensação gostosa de desafio.

4) A tarefa pode lhe parecer árdua, porque este convite pode ser feito com o programa em andamento, mas você sempre foi boa em resolução de problemas, e este é apenas mais um.

5) Você vai descobrir que precisará voltar a estudar e aprender junto com o seu grupo, mas esse é seu discurso diário, não é mesmo? Esta será a hora de colocá-lo em prática.

6) No final do ano, ao ver as produções dos alunos dos seus professores do grupo, você verá coisas maravilhosas que foram feitas, mas também terá visto aquelas que precisam meIhorar, e tanto você quanto eles saberão que o processo é de continuidade.

7) Então você estará pronta para começar tudo de novo, com um novo grupo - afinal, na sua rede os professores não são todos efetivos, e mesmos estes mudam de série.

Te vejo lá.
Esperamos proporcionar a você, leitor, um sentimento semelhante ao que vivenciamos na convivência com Bia. Bia tem sorriso farto e olhos que brilham. Convivemos de maneira próxima, e isso fica explícito no nosso modo de interpretar sua carta. Talvez o leitor se inquiete por considerarmos tais aspectos afetivos em nossa leitura e interpretação da carta de Bia. Não se preocupe, pois não se faz necessário tentar abandonar nossa história de vida para fazer pesquisa narrativa. Ao contrário disso, na narrativa, nossa pesquisa é parte da nossa vida e, como tal, deve estar circunscrita a esse contexto.

Primeiramente, queremos the apresentar Bia. Ela foi professora do ciclo de alfabetização e entrou no PNAIC em um momento de transição, em que o município mudou uma das $\mathrm{OE}$ participantes. Bia é uma professora experiente e já tinha participado de outros programas de formação de professoras.

Encontramos na carta de Bia algo que, de maneira sutil, já chamava nossa atenção enquanto líamos as outras cartas escritas: indícios de uma trajetória permeada pela resiliência docente. Bia inicia o texto, destacando o orgulho de sua experiência, de estar chegando aos 70 anos. Entendemos que o fato dela destacar isso na carta está associado a uma espécie de orgulho da história de vida que está compondo, da sua trajetória de experiências. Por outro lado, sabemos que é muito comum que o estresse da sala de aula e a desvalorização da carreira docente deixe as professoras desmotivadas, principalmente quando já estão na fase da aposentadoria.

Ao contrário disso, Bia permanece encorajada, disposta a trabalhar e investindo na própria formação. Em vários excertos, encontramos vestígios de sua resiliência e, um pouco mais adiante, vamos destacá-los e discuti-los em pormenores. Por enquanto, precisamos explicar que estamos chamando de resiliência à 
capacidade de superar os obstáculos e manter-se entusiasmado e disposto para algo - no caso, para a prática docente (DAY, 2014).

Day (2014, p. 105) endossa que, embora a carreira docente seja fortemente caracterizada pelo abandono, existem professores resistentes que mantêm o compromisso de "fazer a diferença nas vidas de aprendizagem dos seus alunos, durante sua vida profissional", e entendemos que Bia é uma representante desse grupo de professores.

Além de manter-se resiliente, é importante que o professor se mantenha otimista, confiante, esperançoso e motivado por algum propósito moral, para atingir o sucesso da carreira docente (DAY, 2014). Dessa forma, ao lermos a carta de Bia, fomos percebendo que tais construtos estão presentes na narrativa dela, e permeiam cada consideração feita por ela.

Com um gatilho de esperança, a autora inicia a carta, destacando que:

1) Quando você a ler, você estará vivendo o último terço da média de vida dos brasileiros (70 anos), não se assuste com isso; você sempre superou a média.

Para Day (2014), a esperança caracterizase por ter um ideal ou um conjunto de ideais, e, no caso da frase anterior, o ideal é superar a média, extrapolar a expectativa de vida de um brasileiro. 0 ato de ter esperança também se caracteriza por saber conviver com as ansiedades sem desistir, o que está presente no trecho "não se assuste com isso". Entendemos que a esperança é alimentada pelas memórias de futuro e, por sua vez, as memórias de futuro são criadas por existir esperança e por querer o devir.

Outro constructo da resiliência identificado na carta é o otimismo acadêmico, que aparece no seguinte excerto:

3) Você que sempre adorou uma sala de aula com crianças em ciclo de alfabetização $e$ que tem trabalhado com professores um tanto quanto resistentes em olhar para a diversidade e para o direito do outro, poderá ser convidada a trabalhar com um programa de formação de professores deste ciclo - o PNAIC - e voltar a sentir aquela sensação gostosa de desafio.

Os verbos no futuro mostram que há uma expectativa em relação ao desdobramento do trabalho dela, enquanto o adjetivo ("gostosa") indica que tal expectativa é positiva. No trecho citado, o otimismo se faz presente quando Bia cita um problema (professores um tanto quanto resistentes em olhar para a diversidade $e$ para o direito do outro), sem colocá-lo como um obstáculo, mas como algo a ser refletido e transformado.

No mesmo excerto, queremos destacar a função de gestora assumida por Bia, na posição de formadora de outras professoras, refletindo em possiveis desdobramentos da resiliência dela nessa relação. Para Day (2014), o otimismo acadêmico é uma das características dos gestores bem-sucedidos, o que contribui para o sucesso profissional dos membros da equipe escolar, pois:

os líderes escolares têm uma responsabilidade particular de estimular e apoiar a capacidade dos professores que exercem uma resiliência diária, de forma a assegurar que estes são capazes, através de quem são e do que fazem, de ensinar ao seu melhor nível. (DAY, 2014, p. 107)

Isso nos dá indício de que a resiliência de Bia, permeada de otimismo, contribui para que ela seja uma boa formadora, mas também para que as professoras que ela forma sejam motivadas para exercer boas práticas no ciclo de alfabetização.

No PNAIC, sempre estivemos cercados de uma intenção: alfabetizar as crianças até os 8 anos, na perspectiva do letramento. Dessa forma, a interpretação que aqui fazemos não pode perder de vista a formação das crianças. 0 otimismo acadêmico presente na carta de Bia desdobra-se em motivação para que as 
professoras alfabetizadoras trabalhem em seu melhor nivel e isso possa se refletir no processo de aprendizagem das crianças, que, por sua vez, seguem mais animadas a continuar aprendendo.

A leitura da carta de Bia nos mostra que a resiliência acompanhada de otimismo, a esperança e a confiança também são atributos a serem considerados, pois são eles que permitem que a escola seja (re)inventada (CANDAU, 2000) constantemente. O constructo da confiança foi identificado por nós no seguinte excerto:

6) No final do ano, ao ver as produções dos alunos dos seus professores do grupo, você verá coisas maravilhosas que foram feitas, mas também terá visto aquelas que precisam melhorar, e tanto você quanto eles saberão que o processo é de continuidade.

A confiança, que se mistura ao otimismo e à esperança, citados anteriormente, deve-se ao fato de acreditar que o resultado dela vai gerar frutos. É a confiança na capacidade e na competência de si própria, das professoras que ela forma e dos estudantes. Essa confiança entre formadora-professoras-alunos é uma relação de reciprocidade, de troca e diálogo, necessária para um contexto escolar bem-sucedido. Day (2014) explica que essa confiança ajuda os envolvidos a se desenvolverem melhor, bem como enfatiza Bia, no final, ao escrever: "mas também terá visto aquelas que precisam melhorar, e tanto você quanto eles saberão que o processo é de continuidade".

Ao reconhecer que existem "aquelas que precisam melhorar", Bia apresenta uma ideia avaliativa. Para Hoffmann (2014), a avaliação é um processo composto por três etapas: observação do aprendiz de maneira individual; análise e compreensão das estratégias de aprendizagem; e ação pedagógica favorável ao desenvolvimento do estudante. As duas primeiras etapas, por si sós, não fazem sentido, se não forem acompanhadas da terceira, que é a ação que permitirá ao aluno continuar avançando. Quando Bia aponta a continuidade, ela sinaliza que, assim como Hoffmann (2014) reconhece, a avaliação como um ciclo intermitente.

No sétimo tópico, Bia demarca sua resiliência, ao pontuar:

7) Então você estará pronta para começar tudo de novo, com um novo grupo - afinal, na sua rede os professores não são todos efetivos, e mesmos estes mudam de série.

Ao mesmo tempo, Bia faz uma crítica sutil em relação à escola que não constitui uma comunidade. Em sua fala estão presentes as dificuldades para consolidar alguns projetos e as ações, quando a equipe está sempre mudando. Essa falta de estabilidade reforça a necessidade de manter-se em eterno recomeço, motivada, otimista, confiante e esperançosa.

\section{Querida Amanda,}

Lembra-se da frase da sua professora Eva quando te disse e também aos seus colegas de magistério que tudo em Educação leva uns vinte anos para se perceber os frutos das ações?

Era o período de CEFAM, e a Eva e aquela turma de professores eram privilegiados em participar de um programa de formação específica em nível técnico de professores.

Ela estava certa!!! Há três anos atrás, em 2012, quando você aderiu ao PNAIC, você pôde ver novamente aquelas ideias, aquele clima de que estão falando a mesma língua, não somente em São Paulo, mas em todo o Brasil, com professores de todo o Brasil. Você não imaginaria que teria uma turma de professores tão animados como os seus; com eles você descobriu o "lago dos cisnes".

A Eva não sabia que há vinte e um anos atrás a mobilidade de informações era tão lenta, mas a tecnologia tem ajudado a tornar tudo mais rápido. 
E... eu nem falei do whatsApp, muito mais rápido para as trocas e a interação.

Aproveita tudo.

Amanda.

A partir da carta de Amanda, percebemos quatro momentos que nos chamaram a atenção e que serão interpretados. Por outro lado, Amanda, em um determinado momento da carta, faz referência ao ballet 0 lago dos cisnes, de Tchaikovsky, que é dividido em quatro atos. Sendo assim, entendemos que a carta de Amanda nos provoca a organizar sua interpretação em quatro atos.

A carta de Amanda, como um todo, já é um ato, na perspectiva da categoria de ato responsável, que requer atitudes responsivas, proposta por Bakhtin (2010). Ao escrever a sua carta, Amanda é responsiva à proposta apresentada, há ali um ato responsável do eu para mim e do eu para o outro. E, à medida que interpretamos a sua carta, buscamos a empatia - um mergulhar no outro, a criação de uma unidade com outro -, que, por sua vez, possibilita um ato responsável nosso para com Amanda (ato responsável do outro para mim).

Nesse sentido, a carta de Amanda nos provoca a organizá-la em quatro atos de um ballet, pois, desse modo, entendemos que conseguimos mergulhar no outro e estabelecer uma unidade com Amanda através de sua narrativa.

\section{Primeiro ato}

Lembra-se da frase da sua professora Eva, quando te disse e também aos seus colegas de magistério que tudo em Educação leva uns vinte anos para se perceber os frutos das ações?

Amanda era professora dos Anos Iniciais na Região Metropolitana de São Paulo no momento da escrita da carta. Além disso, estava designada para ser Orientadora de Estudos das professoras alfabetizadoras da sua escola.
Nesse primeiro ato, Amanda coloca uma pergunta para ela mesma três anos antes. Nessa pergunta, percebemos a importância de um outro, a professora Eva, em seu desenvolvimento profissional. Amanda demonstra a importância de Eva em sua vida, na medida em que recorda uma das falas dessa professora que também foi sua formadora.

\section{Segundo ato}

Era o período de CEFAM, e a Eva e aquela turma de professores eram privilegiados em participar de um programa de formação específica em nível técnico de professores.

No segundo ato, Amanda nos dá indício de que ela entende que, como na Educação, as mudanças que ela sofreu serão percebidas depois de alguns anos. Nesse excerto, ela nos relata o período de formação de que participou no Centro Específico de Formação e Aperfeiçoamento do Magistério - CEFAM. Os CEFAM foram criados pela Secretaria de Educação do Estado de São Paulo em 1988, pelo Decreto 28.089/88, e tinham como objetivo a formação dos professores da rede (PETRUCI, 1994). Amanda participou de um programa de formação no CEFAM, no início da década de 1990.

Esse ato também nos dá indício que não é somente pela implantação de uma política pública ou de centro de formação que as mudanças ocorrerão, mas há a necessidade de pensar nos próprios formadores de professores e nas contribuições que deixarão para os participantes, bem como na organização de turmas em que os profissionais tenham necessidades parecidas, problemas compartilhados e desafios a serem ultrapassados coletivamente.

\section{Terceiro ato}

Ela estava certa!!! Há três anos atrás, em 2012, quando você aderiu ao PNAIC, você pôde ver novamente aquelas ideias, aquele clima de que 
estão falando a mesma língua, não somente em São Paulo, mas em todo o Brasil, com professores de todo o Brasil. Você não imaginaria que teria uma turma de professores tão animados como os seus; com eles você descobriu o "lago dos cisnes".

Ao se referir ao CEFAM, Amanda indica que percebeu características semelhantes entre esse centro e a proposta do PNAIC. Vinte anos foi o período que Amanda demorou para perceber outra proposta que a fizesse se sentir como estava no período de CEFAM. Vinte anos foi o período que ela demorou para perceber que estava em um lugar de reflexão conjunta sobre as próprias práticas e em um lugar em que percebia que "estavam falando a mesma língua", com os mesmos problemas, angústias e desafios.

Nesse ato, Amanda faz referência ao ballet $O$ lago dos cisnes, de Tchaikovsky. O ballet conta a história de Odette, uma princesa que foi transformada em cisne por um feiticeiro. No lago, formado pelas lágrimas de sua mãe, Odette vive com outras princesas transformadas em cisnes também. O feitiço só será quebrado quando um príncipe se apaixonar por ela.

O que nos cabe perceber nessa história é que Amanda nos dá sinais de que as dificuldades (os feitiços) que as professoras enfrentam no seu dia a dia vão continuar existindo, e o príncipe, a solução mágica para superar essas dificuldades, nesse caso, não irá aparecer. É no lago, com outras professoras (cisnes), que as dificuldades serão superadas, a partir da reflexão conjunta das dificuldades e dos desafios que as professoras enfrentam na profissão. É com os cisnes, os outros que passam pela mesma situação que Amanda, que ela compreende que as mudanças ocorrerão.

\section{Quarto ato}

A Eva não sabia que há vinte e um anos atrás a mobilidade de informações era tão lenta, mas a tecnologia tem ajudado a tornar tudo mais rápido.

E... eu nem falei do whatsApp, muito mais rápido para as trocas e a interação.

Por fim, no quarto ato, Amanda escreve em sua carta que, mesmo que Eva tivesse razão sobre o tempo necessário para as mudanças ocorrerem na Educação, ela não poderia prever as mudanças tecnológicas ocorridas em 20 anos. Não poderia prever que tais tecnologias auxiliariam a criar redes de professoras para além das atividades de formação presenciais. Seja a rede criada por meio de aplicativos, como mencionado por Amanda, ou por meio de plataformas, como o Moodle do Portal dos Professores da UFSCar e os cursos oferecidos entre 2013-2015, que, segundo Martins et al (2017, p. 8), podem ser considerados como um artefato cultural em rede, "visando à troca e produção de conhecimento interdisciplinar, em um ambiente virtual multifacetado, no qual há movimentos em constante transformação, constituído por diferentes motivações e interesses".

O quarto ato dá mostras de que o "lago dos cisnes", além de ser um lugar físico, tornou-se, através das Tecnologias Digitais de Informação e Comunicação, em um lugar virtual de troca e compartilhamento.

A carta de Amanda nos dá indício de como foi e é o seu lago...

\section{Olá Cátia!}

Nesse momento você deve estar na expectativa de que uma pessoa especial esteja pensando em você de forma especial. Será que o mesmo sentimento que tens por ele é reciproco? Pode ser coisa da sua cabeça.

No campo profissional surge uma dúvida: será que vai dar conta do compromisso, no qual se inscreveu e foi escolhida para ser uma das escolhidas para uma das cinco vagas 
como orientadora de estudo do Pacto Nacional pela Alfabetização na Idade Certa do município [nome do município], onde atua como coordenadora pedagógica da escola?

Atuar como coordenadora de uma escola, de fato, não é nada fácil. A formação continuada dos professores é, sem dúvida, a principal atribuição de um coordenador. Infelizmente, os professores ainda carregam uma concepção que não atinge as diversidades que encontramos no dia a dia nas escolas.

Quando iniciar o PNAIC, não deixe de assistir às aulas de uma das orientadoras, Janice, que atuará aos sábados. Será dificil conciliar a função de coordenadora, o PNAIC, a pós-graduação em Ed. Infantil e o papel de mãe e pai. Mas será imprescindivel ampliar o seu conhecimento com a Janice, uma pessoa que, na sua simplicidade, sabe muito.

O PNAIC irá proporcionar muitos conhecimentos. Em 2014, a formação de Matemática será incrivelmente gratificante. $E$, ainda em 2013, receberá um convite da diretora Carina, um convite para realizar um workshop de Matemática na Unifai. Essa participação só confirmará a previsão da amiga Mariana, que, como sempre, acerta tudo. A sua área não é mais com a Ed. Infantil, e sim no ensino superior. Foi uma experiência incrivel!!!

Sua filha vai colaborar muito para que dê conta de tudo com tranquilidade, pois se esforçará tanto quanto você, reconhecendo seu esforço e dedicação. Vai ser motivo de muito orgulho.

Com certeza, nesse momento, vocês devem estar na expectativa e ansiedade para a partida dela, que tentará realizar o sonho de morar no Japão.

Continue estudando muito, pois seu esforço será reconhecido, irá trabalhar na Secretaria de Educação, especialmente com formação de professores e com o PNAIC.

Muitos professores que iniciarão em 2013 no PNAIC continuarão no seu grupo, quem sabe até 2016. Profissionais que te darão muito orgulho e esperança por uma educação melhor.

Ah! já ia me esquecendo. Preste atenção naquele jovem e bonito que joga vôlei com você.

Até breve e seja muito feliz.

Você, ontem.

Cátia, uma nissei séria, criativa e responsável, exercia o cargo de coordenadora pedagógica no município durante os três anos em que participou do PNAIC. Trabalhou anteriormente como professora nas escolas municipais e estaduais de São Paulo. Em sua carta, no primeiro parágrafo, Cátia já nos dá indício de um dos elementos de sua narrativa: o contexto (CRECCI, 2016) em que a autora estava vivendo há três anos. 0 relato deixa clara a existência de um momento de romance, de dúvidas, expectativas e inseguranças. Isso nos permite imergir no contexto circunscrito ao qual ela se refere.

Isso também demonstra que houve uma intenção de socializar conosco tal experiência. A autora inicia com um aspecto de sua vida afetiva. Um indício de que, no ponto de vista dela, vida pessoal e profissional estão intimamente relacionadas, bem como apontado por Dewey (1971). Também há uma necessidade pessoal de chamar a atenção em relação a esse período de incertezas em sua vida.

Em seguida, Cátia narra:

No campo profissional surge uma dúvida: será que vai dar conta do compromisso, no qual se inscreveu e foi escolhida para ser uma das escolhidas para uma das cinco vagas como orientadora de estudo do Pacto Nacional pela Alfabetização na Idade Certa do município [nome do município], onde atua como coordenadora pedagógica?

Nesse excerto, Cátia indica o cenário/lugar físico em que está, ao nos mostrar que atua como coordenadora pedagógica no município. 
Além disso, ela questiona sua própria formação, pois teve dúvida se iria ser selecionada para uma das poucas vagas para OE em seu município. Ao mesmo tempo, alimenta a autoestima do seu eu, no passado, ao lembrá-la que é coordenadora pedagógica e também não é uma tarefa fácil assumir esse cargo, que a põe em constante relação com as outras professoras da escola.

Em outro trecho, Cátia afirma:

A formação continuada dos professores, é sem dúvida, a principal atribuição de um coordenador. Infelizmente, os professores ainda carregam uma concepção que não atinge as diversidades que encontramos no dia a dia nas escolas.

No trecho acima, Cátia nos dá indício de que uma de suas necessidades, passada e presente, é saber lidar com a diversidade dos alunos e fazer com que a formação continuada das professoras em seu município leve em conta essa necessidade. Tardif e Lessard (2008, p. 9) argumentam que essa é uma das necessidades, dentre várias, que o docente encontra atualmente, pois, assim como a sociedade, o ensino se tornou complexo e uma atividade rigorosa que exige "daqueles e daquelas que a exercem, a existência de um verdadeiro profissionalismo".

O excerto de Cátia nos revela as próprias expectativas que ela tem em relação ao PNAIC. Ao mostrar a necessidade de pensar na diversidade, Cátia nos indica que quer que ela, três anos antes, atente para as discussões que o PNAIC traria sobre a diversidade dos estudantes no ambiente escolar e como trabalhar com essa diversidade.

A partir desse indício na carta de Cátia, observamos que os cadernos do PNAIC (cadernos de 2014-2015) propiciam a discussão sobre a diversidade dos alunos, bem como a reflexão sobre o ensino e a aprendizagem desses alunos. Seja no momento em que desenvolve a discussão sobre alfabetização de crianças com deficiência, quando discute a Educação Matemática inclusiva (BRASIL, 2014) ou ainda quando aborda o currículo na perspectiva da diversidade (BRASIL, 2015), por exemplo.

Sabemos, a partir do convívio com ela que, durante os anos em que Cátia estava na formação do PNAIC, ela também participou de dois Encontros de Educação Matemática nos Anos Iniciais (II e III EEMAI), ocorridos na UFSCar. Ali as discussões sobre a diversidade também estiveram presentes em palestras, mesas-redondas e minicursos. Entendemos que, tanto a necessidade expressa por Cátia de pensar sobre a diversidade, quanto os materiais do PNAIC, os eventos de que participou e as discussões nos encontros de formação, fizeram com que ela acreditasse ser importante lembrá-la no passado da dificuldade de pensar a formação continuada das professoras da escola em relação à diversidade e também nos dá indício de que ela quer chamar sua própria atenção para as discussões sobre a diversidade que ocorrerão por meio das atividades de formação do PNAIC.

Em outro trecho, por outro lado, ela destaca a importância de reconhecer as práticas de sua colega Janice e a necessidade de participar da formação ministrada por ela:

Quando iniciar o PNAIC, não deixe de assistir às aulas de uma das orientadoras, Janice, que atuará aos sábados. Será difícil conciliar a função de coordenadora, o PNAIC, a pós-graduação em Ed. Infantil e o papel de mãe e pai. Mas será imprescindivel ampliar o seu conhecimento com a Janice, uma pessoa que, na sua simplicidade, sabe muito.

Nesse excerto, Cátia indica a necessidade de pensar a profissão docente pela/na troca entre os pares, rompendo com a lógica que entende o trabalho docente como um trabalho solitário. Há uma relação de confiança com Janice (OE mais velha que Cátia e com mais experiência sobre alfabetização), e é com Janice 
que conseguirá o apoio de que necessita para enfrentar esse novo desafio: ser OE do PNAIC. Cátia nos mostra uma das possibilidades de deslocar a ideia de desenvolvimento de competências individuais dos professores (MORETTI; MOURA, 2010) para o entendimento de que o professor constrói saberes com os outros e que a atividade docente é compartilhada.

Posteriormente, além de evidenciar a necessidade de pensar na diversidade dos estudantes, Cátia chama a atenção para um dos objetivos na formação do PNAIC - pensar a Educação Matemática nos Anos Iniciais:

Em 2014, a formação de Matemática será incrivelmente gratificante.

As palavras incrivelmente e gratificante nessa frase são importantes para refletir sobre um programa governamental que colocou em destaque a formação dos professores em relação à Educação Matemática nos Anos Iniciais.

Ao usar o adjetivo "gratificante", potencializado pelo advérbio “incrivelmente", Cátia enfatiza o aspecto positivo de tal formação para seu desenvolvimento profissional. Nos encontros de formação em que refletimos sobre a Educação Matemática nos Anos Iniciais, Cátia demonstrava interesse não só pelas discussões sobre os aspectos pedagógicos e didáticos sobre o ensinar e aprender Matemática nos Anos iniciais, mas também pela compreensão dos conceitos que sentia dificuldade de entender.

Nós três, pesquisadores e educadores matemáticos que aqui escrevemos, gostaríamos que houvesse mais indícios na carta de Cátia que nos auxiliassem a refletir sobre a Educação Matemática nos Anos Iniciais. Isso não ocorreu. Porém entendemos que esta é uma característica das narrativas: o narrador decide o que e como dizer, o que lembrar e o que esquecer, o que está mais latente no momento da narração e o que não está.

Posteriormente, Cátia entende que seria importante chamar sua própria atenção, no passado, em relação à necessidade de continuação de seus estudos:

Continue estudando muito, pois seu esforço será reconhecido, irá trabalhar na Secretaria de Educação, especialmente com formação de professores e com o PNAIC.

Ao ler este trecho, buscamos imediatamente um reencontro com Christopher Day (2001), na obra Desenvolvimento profissional de professores: os desafios da aprendizagem permanente. Quando Cátia diz que precisa continuar estudando, recordamo-nos desse autor, pois ele aponta que as práticas de formação contínua contribuem significativamente para o desenvolvimento profissional dos professores, se alinhadas com suas expectativas e necessidades.

Tal alinhamento se faz presente no discurso de Cátia, quando ela expõe sua necessidade. Ela precisa continuar estudando para quê? Para atuar na Secretaria de Educação e formar outras professoras. Mostra-nos, assim, que não the interessa qualquer formação. Não lhe interessa apenas uma certificação. Portanto, cabe nossa reflexão: qual a diferença entre a formação por necessidade e a meramente burocrática? Os teóricos já se aprofundaram nessa reflexão e já é ponto consensual que as ações formativas devem considerar as especificidades de cada escola, de cada professora, visando a um letramento que valorize a diversidade, ao invés de poli-la. Até que ponto conseguimos propor uma formação nesse sentido no PNAIC? Essa é a inquietação que nos acompanha e perdura ao ler essa carta...

Por fim, Cátia ressalta:

Muitos professores que iniciarão em 2013 no PNAIC continuarão no seu grupo, quem sabe até 2016. Profissionais que te darão muito orgulho e esperança por uma educação melhor.

Nesse trecho da carta, ela escreve para si mesma, dizendo que muitas pessoas continuarão até 2016, mas não todas. Isso nos mostra 
seu desejo da continuidade das professoras no PNAIC. O PNAIC sofreu mudanças entre 2013 e 2016, tanto na entrada e saída de OE quanto em sua própria estrutura e financiamento. Pensando no tempo histórico em que a narrativa foi escrita por Cátia, percebemos que esse fragmento da carta também aponta uma preocupação dela em relação à continuidade de todas as professoras no PNAIC em 2016. Em um contexto mais amplo, vemos o Brasil no meio de uma crise político-econômica e as incertezas sobre a continuidade do governo Dilma Rousseff refletidas nas falas das OE. Em conversas com as $\mathrm{OE}$, algumas preocupações recorrentes eram em relação à demora na entrega dos materiais por parte do Governo Federal para as redes estaduais e municipais; ao atraso nas bolsas concedidas para as OE e para as professoras alfabetizadoras; e à continuidade em si dessa rede de formação.

Sabemos que a descontinuidade das ações formativas propostas para os professores na década de 1970 e 1980 foram ineficazes para a mudança de prática, saberes e concepções dos professores (FIORENTINI; NACARATO, 2005) e que não atendiam as necessidades das escolas e dos professores (RIBAS, 2000). Mas Cátia, por sua vez, dá indícios de que, ao contrário das propostas das décadas de 1970 e 80, o PNAIC atendia, em certa medida, as necessidades que ela tinha como professora e coordenadora pedagógica da escola.

Ela finaliza a carta indicando uma memória de futuro: são os seus colegas de profissão e formação que darão esperança por uma educação melhor.

\section{Post scriptum ou das surpresas que chegam quando acreditamos que uma narrativa está finalizada}

Cartas... Dizia Álvaro de Campos que todas as cartas de amor são ridículas (CAMPOS, 1937, $s / p)$. Não sabia ele o que aconteceria com as cartas, não somente as de amor, na sociedade da informação... e-mail... cartas que têm um tempo de escrita e resposta diferente das cartas em papel, mas que nos revelam algumas surpresas, como esta: ${ }^{10}$

Bia, boa tarde. Como você está? Já pensou enxergar você mesma com os olhos de outro alguém? Kublai Khan é um grande imperador narrado por Ítalo Calvino no livro "As cidades invisiveis", que conheceu parte de seu reino pelos olhos de Marco Polo. Ao lermos sua carta, fizemos como neste livro, imaginamos que você era a grande imperadora e procuramos narrar para você o seu reino, mas a partir de nossos olhos. Queremos compartilhar com você a interpretação de sua carta. Sua narrativa nos deu muitas pistas do que foi o PNAIC. Nos fez refletir sobre onde estamos, sobre o caminho que trilhamos juntos e o que ainda está por vir. Sua carta transborda passado. Passado que se faz presente, que te constituiu e que te fez superar a média, não é mesmo? Esperamos que nossas leituras e interpretações tenham construído uma ponte entre suas palavras e as nossas. Forte abraço. Everaldo e Lívia.

Everaldo e Lívia, boa noite! Estou emocionada e lisonjeada com a interpretação que acabei de ler sobre mim mesma. Não costumo ser dada às lágrimas, mas hoje quase sucumbi. É muito bom saber que o que procuramos ser na vida acaba se tornando real pelo menos em parte (Tenho certeza que não o somos no todo, afinal somos aprendizes ainda). Obrigada pela emoção desta noite. Eu estava precisando. Espero revê-los em algum momento. Estou anexando um programa para que vocês saibam no que estou metida neste momento. Um grande abraço a todos. Bia.

E lá se vão Bia, Cátia e Amanda, seguindo os seus caminhos. Dessa vez, no caso de Bia, na organização da 6. a Women Leading Education Conference: from Margins to Centers (6.a Conferência de mulheres líderes em Educação: das periferias aos Centros)...

10 E-mails trocados com Bia após a interpretação de sua carta. 


\section{Referências}

IL POSTINO (O carteiro e o poeta - título no Brasil). Direção de Michael Radford. Itália. Produtora: Walt Disney. Roteiro adaptado: Anna Pavignano. 1994.

BAKHTIN, Mikhail. Estética da criação verbal. São Paulo: Martins Fontes, 1997.

BAKHTIN, Mikhail. Marxismo e filosofia da linguagem. 12. ed. São Paulo: Hucitec, 2006.

BAKHTIN, Mikhail. Para uma filosofia do ato responsável. Tradução de Valdemir Miotello e Carlos Alberto Faraco. São Carlos: Pedro e João Editores, 2010.

BETHÂNIA, Maria. Oração ao tempo. São Paulo: Biscoito Fino. 2006. Disco: Tempo, Tempo, Tempo, Tempo. 2006. Autoria: Caetano Veloso. 3min:15s.

BETHÂNIA, Maria. Oração ao tempo. Disco: Tempo, Tempo, Tempo, Tempo. 2006. Compositor: Caetano Veloso.

BRASIL. Ministério da Educação. Caderno de Educação Especial: a alfabetização de crianças com deficiência: uma proposta inclusiva. Brasília, DF: MEC, SEB, 2012.

BRASIL. Ministério da Educação. Pacto Nacional pela Alfabetização na Idade Certa: Educação Inclusiva. Brasília, DF: MEC, SEB, 2014.

BRASIL. Ministério da Educação. Currículo na perspectiva da inclusão e da diversidade: as Diretrizes Curriculares Nacionais da Educação Básica e o Ciclo de Alfabetização. Brasília, DF: MEC, SEB, 2015.

BRASIL. Ministério da Educação. Planejando a próxima década: conhecendo as 20 metas do Plano Nacional de Educação. 2014. Disponível em: <http:// pne.mec.gov.br/images/pdf/pne_conhecendo_20_ metas.pdf>. Acesso em: 19 mai. 2017.

CAMPOS, Álvaro. Todas as cartas de amor são ridículas. 1a publ. Acção, Lisboa, n. 41, 1937.

CANDAU, Vera Maria Ferrão. (Org.). Reinventar a escola. Petrópolis, RJ: Vozes, 2000.

CLANDININ, D. Jean. CONNELLY, F. Michael. Pesquisa narrativa: experiências e história na pesquisa qualitativa. Tradução do Grupo de Pesquisa Narrativa e Educação de Professores ILEEL/UFU. Uberlândia, MG: EDUFU, 2015.

$\mathrm{CRECCl}$, Vanessa Moreira. Desenvolvimento profissional de educadores matemáticos participantes de uma comunidade fronteiriça entre escola e universidade. 2016. 325 f. Tese (Doutorado em Educação) - Programa de Pós-Graduação em Educação, Universidade Estadual de Campinas, Campinas, 2016.

DAY, Christopher. Desenvolvimento profissional de professores: os desafios da aprendizagem permanente. Porto: Editora Porto, 2001.

DAY, Christopher. Resilience, teachers and the quality of education [A resiliência, os professores e a qualidade da Educação]. In: FLORES, Maria Assunção; COUTINHO, Clara Pereira. (Ed.). Formação e trabalho docente: diversidade e convergências [Training and teaching work: Diversity and convergence]. Santo Tirso, Portugal: De Facto Editores, 2014. p. 101-130.

DEWEY, John. Experiência e educação. São Paulo: Nacional, 1971.

FIORENTINI, Dario; NACARATO, Adair Mendes. (Orgs.). Cultura, formação e desenvolvimento profissional de professores que ensinam matemática: investigando e teorizando a partir de prática. São Paulo: Musa, 2005.

FREITAS, Maria T. M.; FIORENTINI, Dario. As possibilidades formativas e investigativas da narrativa em Educação Matemática. Quadrante, Lisboa, v. 15, p. 63-71, 2007.

GALVÃO, Cecília. Narrativas em Educação. Ciência e Educação, Bauru, v. 11, n. 2, p. 327-345, 2005.

GAMA, Renata Prenstteter; SOUSA, Maria do Carmo de. Aprendizagens docentes de futuros professores de Matemática reveladas em narrativas escritas na formação compartilhada de professores. Interacções, Santarém, n. 18, p. 131-156, 2011.

GERALDI, João Wanderley. Concepções de linguagem e ensino de Português. In: 0 texto na sala de aula. São Paulo: Ática, 1984. 
GINZBURG, Carlo. Mitos, emblemas, sinais: morfologia e história. São Paulo: Companhia das Letras, 1989.

GINZBURG, Carlo. 0 queijo e os vermes: o cotidiano e as ideias de um moleiro perseguido pela Inquisição. São Paulo: Companhia das Letras, 2006.

HOFFMAN, Jussara. 0 jogo do contrário em avaliação. 9. ed. Porto Alegre: Mediação, 2014.

MARTINS, Maria S. et al. Práticas docentes na extensão Universitária: três experiências interdisciplinares. Interletras, Grande Dourados, MS, v. 6, p. 1-13, abr./set. 2017.

MORETTI, Vanessa Dias; MOURA, Manoel Oriosvaldo. A formação docente na perspectiva histórico-cultural: em busca da superação da competência individual. Psicologia Política, São Paulo, v. 10, n. 20, p. 345-361, 2010.

NACARATO, Adair Mendes. As narrativas de vida como fonte para a pesquisa autobiográfica em Educação Matemática. Perspectivas da Educação Matemática, Campo Grande, v. 8, p. 449-467, 2015.

NACARATO, Adair Mendes; PASSEGGI, Maria da Conceição Ferrer Botelho Sgadari. Narrativas autobiográficas produzidas por futuras professoras: representações sobre a matemática escolar. Revista Educação, PUC-Campinas, n. 18, v. 3. p. 287-299, set./ dez. 2013.

PETRUCl, Maria das Graças Ribeiro Moreira. CEFAM - Uma proposta de formação e aperfeiçoamento de professores para o 10 Grau. Paidéia - Universidade de São Paulo, Faculdade de Filosofia Ciências e Letras de Ribeirão Preto, Ribeirão Preto, n. 6, p. 9-25, 1994. Disponivel em: <http://hdl.handle. net/11449/29515>. Acesso em: 16 ago. 2018.

RIBAS, Mariná Holzmann. Construindo a competência: processo de formação de professores. São Paulo: Olho d'Água, 2000.

SANTOS, Luciane Mulazani dos.; MIARKA, Roger; SIPLE, Ivanete Zuchi. O uso de blogs como tecnologia educacional narrativa para a forma/ação inicial docente. Bolema, Rio Claro, v. 28, n. 49, p. 926-949, ago. 2014.

SILVA, Américo Junior Nunes da.; PASSOS, Carmen Lúcia Brancaglion. Querido diário: 0 que dizem as narrativas sobre a formação e futura prática do professor que ensinará matemática nos Anos Iniciais. Hipátia - Revista Brasileira de História, Educação e Matemática, Campos do Jordão, v. 1, p. 46-57, 2016.

SUASSUNA, Lívia. Pesquisa qualitativa em Educação e Linguagem: histórico e validação do paradigma indiciário. Perspectiva, Florianópolis, v. 26, n. 1, p. 341-377, jan./jun. 2008.

TARDIF, Maurice; LESSARD, Claude. 0 oficio de professor: história, perspectivas e desafios internacionais. 2. ed. Petrópolis, RJ: Vozes, 2008.

Recebido em: 17/08/2018

Aprovado em: 26/03/2019

Everaldo Gomes Leandro: Doutorando em Educação pela Universidade Federal de São Carlos (UFSCar). e-mail: everaldogomesleandro@hotmail.com

Av. Francisco Pereira Lopes, 2100, 32a, Jardim Santa Paula, São Carlos, SP, Brasil, CEP: 13561-250.

Lívia de Oliveira Vasconcelos: Doutoranda em Educação pela Universidade Federal de São Carlos (UFSCar). e-mail: profliviavasconcelos@gmail.com

Rua Humberto Manelli, 116, apto. 27, Jardim Gibertoni, São Carlos, SP, Brasil. CEP: 13574-640. 